\title{
Optimization design of the stick of an excavator under uncertain loading (in the conditions of the Syrian Arab Republic)
}

\author{
Jalal Mohammad ${ }^{1}$, Irina Odinokova ${ }^{1}$, Vitaly Gaevskiy ${ }^{1}$, and Evgeni Nosko ${ }^{1}$ \\ ${ }^{1}$ Moscow Automobile and Road Construction State Technical University (MADI) 64, Leningradskiy \\ pr., Moscow, 125319, Russia.
}

\begin{abstract}
The article is devoted to the optimization design of the stick of a hydraulic excavator at the most frequent and greatest value loads. The uncertain loads acting on the working equipment of the excavator were obtained by the Monte Carlo method based on 3D analytical soil-tool interaction models. The results show that the adopted methodology can be used to optimize the design of elements of the excavator working equipment, since the design of stick was obtained with less weight and lower stress values than the original design.
\end{abstract}

\section{Introduction}

The excavators are supposed to have high performance, force output capability, energy consumption, and working life. In effect, lighter elements of the working equipment can have lower fabricating cost and lower operating costs, thus larger digging force can be created with the same hydraulic driving system. As well elements with greater strength have higher durability. As well elements with greater strength have higher durability. Therefore, it is necessary to design the elements of working equipment of excavator with the lowest weight and maximum strength. Determining of the external loads acting on the working equipment is the first step to carry out structural optimization. As a criterion for optimization of the elements of the working equipment of excavator, the largest digging force that can be created by the hydraulic system of the excavator (when the bucket or stick cylinders activated independently) is usually used [1-6]. This optimization approach using overestimated value of the margin of safety leads to increase in the mass of the element and a consumption of material.

When excavating the soil using an excavator, the forces acting on the bucket are uncertain due to the constantly changing properties of the soil, thus stresses in the elements of the working equipment (bucket, stick, boom) are variable. The traditional deterministic design method of structural elements of the working equipment does not take into account these uncertainties when calculating the digging force, acting on the bucket, but it is calculated under limiting working condition according to the theoretical or empirical load model. In order to obtain elements with high-strength and lower-weight during optimization or design, the loads on the elements must be calculated with the consideration

*Corresponding author: galaloomohamad83@gmail.com. 
of uncertainties. The main purpose of this paper is to create an approach to quantify the uncertainty in design loads that occur when digging the soil with an excavator bucket and to assess the possibility and usefulness of using this approach when optimizing the structural of elements of working equipment of the excavator.

\section{Analytical model for assessing digging force}

Several models have been created for calculating digging force [7-10]. these models provide a solid foundation for online soil-bucket interaction identification, improve prediction of resistance force based on learning method [11], simulation of the digging process with an excavator [12], assessment of digging efforts and payload of excavators by state observers [13], simulation of dynamic motion planning of working equipment of excavator [14], and in the development of highly realistic simulation of the process of digging the soil with an excavator [15]. These models cannot eliminate the uncertainty in soil parameters, even when using these models to estimate digging forces. The most probable range of digging forces was given based on experimental results and a set of performance metrics was proposed to describe the performance of the excavator in this most probable range [16]. These studies provide a strict approach to the design or optimization of the element structure, as they did not take into account the uncertainties in soil parameters.

Various methods were used to analyze the surface of soil failure and determine digging force. Based on the logarithmic spiral method, Reece proposed a generalized fundamental equation for calculating the cutting force of soil as follows [17]:

$$
F(N)=\gamma b^{3} N_{\gamma}+c b^{2} N_{c}+q b^{2} N_{q}+c a b^{2} N_{a}
$$

where F: resistance force experienced by the tool, or the force required to cut the soil $[\mathrm{N}]$, c: soil cohesion $\left(\mathrm{N} / \mathrm{m}^{2}\right)$, b: depth of cut $[\mathrm{m}], \gamma=$ soil density $\left(\mathrm{N} / \mathrm{m}^{3}\right)$, q: the surcharge pressure $\left(\mathrm{N} / \mathrm{m}^{2}\right)$, ca: soil to metal adhesion $\left(\mathrm{N} / \mathrm{m}^{2}\right), \mathrm{Nc}, \mathrm{N} \gamma, \mathrm{Nq}$, and $\mathrm{Na}$ : dimensionless Reece factors: describing the shape of the soil failure surface, and depend on the angle of internal shearing resistance $\varnothing$, angle of soil to metal friction $\delta$, as well as on the shape of the structure and soil mass.

On the basis of the Reece equation, two-dimensional and three-dimensional soil-tool interaction models were developed [18-19]. McKyes (1977) approximated the curved line of the lowest soil slip line caused by the cutting tool is a straight line i.e., the failure surface of the soil is flat and he used the basic Reece equation, also gave exact equations of factors (Ni). The model assumes that the cut soil is treated as a failure wedge, as shown in Figure 1.

Studying this soil wedge in static equilibrium analysis the forces acting on the wedge can be calculated, as follows:

$$
P=\left[\frac{-(A D F) \cdot \cos (\beta+\varphi+\rho)+2\left(S F_{2}\right) \cdot \cos \varphi+G \cdot \sin (\varphi+\rho)+2\left(C F_{2}\right) \cdot \cos \varphi+\left(C F_{1}\right) \cdot \cos \varphi}{\sin (\beta+\varphi+\rho+\delta)}\right]
$$




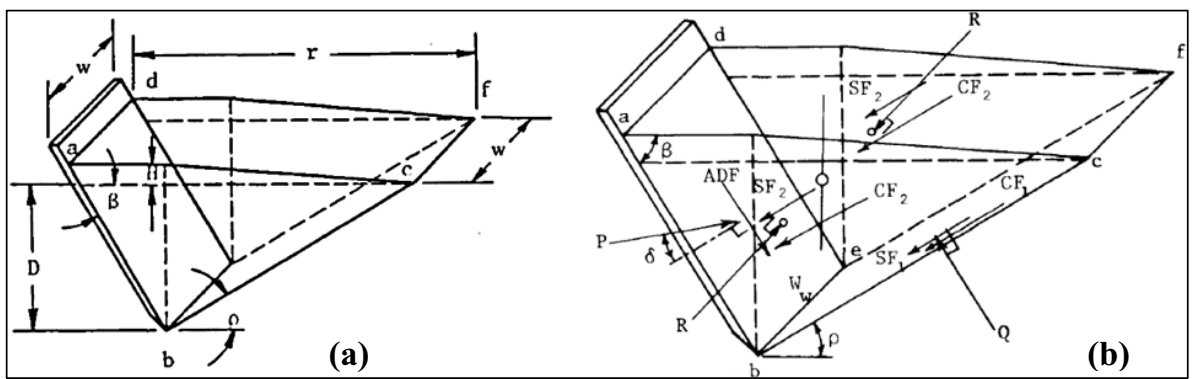

Fig. 1. (a): The geometric of a failure wedge; (b): forces acting on the failure wedge.

On the surface (adfc) are three forces are determined by the formulas:

$$
R=\gamma \cdot K_{o} \cdot Z A ; S F_{2}=R \cdot \tan \emptyset ; C F_{2}=A \cdot c
$$

The force vector $\mathrm{Q}$ is the force perpendicular to the surface (befc), on which the forces also act:

$$
C F_{1}=\frac{c \cdot w \cdot D}{\sin \rho} ; \quad S F_{1}=Q \cdot \tan \phi
$$

Where Q - normal force of separation resistance force as a result of friction.

On the surface (abed) forces act: (ADF) the adhesion force between soil and tool, and (P) a force exerted on the tool in the direction of movement.

$$
A D F=\text { ca } \cdot w \cdot D \cdot(1+H / D) \sin \beta
$$

The weight of the soil (surcharge) acting on surface of the wedge of soil failure is determined by the formula:

$$
G=\gamma \cdot w \cdot A
$$

where in equations 3-6,

$\mathrm{R}$ : The forces are perpendicular to the surfaces ( $a b c)$ and (def);

$K_{o}$ : coefficient of soil pressure at rest;

$Z=(D+H) / 3$ : average depth at which the center of gravity of the wedge is from the soil surface;

A: area of each surface (abc) and (def).

$\mathrm{H}$ : height of soil swelling in front of the tool; w: tool width;

CF2: the cohesion force on the sides (abc) and (def);

$\mathrm{SF}_{2}$ : the frictional force on the sides (abc) and (def);

$\mathrm{CF}_{1}$ : the cohesion force on the rupture plane;

$\mathrm{SF}_{1}$ : the frictional force on the rupture plane.

From equations (1-6), the soil cutting force can be determined by the formula:

$$
P=\left(\gamma \cdot d^{2} \cdot N_{\gamma}+c \cdot d \cdot N_{c}+q \cdot d \cdot N_{q}+c a \cdot N_{a}\right) w
$$

and can be used model of failure wedge shown in Figure 2.

Where, $\mathrm{P}$ : soil resistance forces to digging $[\mathrm{N}]$;

$\alpha$ - the rake angle;

$\beta$ - the angle of failure soil;

$\mathrm{d}$ - digging depth $[\mathrm{m}]$;

$\mathrm{q}$ - surcharge pressure on soil free surface $\left[\mathrm{N} / \mathrm{m}^{2}\right]$;

and $(\mathrm{N})$ factors can be determined by:

$$
N_{\gamma}=\frac{[\cot \beta-\tan \rho][\cos \rho+\sin \rho \cot (\beta+\varnothing)]}{2[\cos (\alpha+\delta)+\sin (\alpha+\delta) \cot (\beta+\varnothing)]} ; N_{c}=\frac{[1+\cot \beta \cot (\beta+\varnothing)]}{\cos (\alpha+\delta)+\sin (\alpha+\delta) \cot (\beta+\varnothing)}
$$




$$
N_{q}=\frac{\cot \alpha+\cot \beta}{\cos (\alpha+\delta)+\sin (\alpha+\delta) \cot (\beta+\emptyset)} ; N_{a}=\frac{1-\cot \alpha \cot (\beta+\emptyset)}{\cos (\alpha+\delta)+\sin (\alpha+\delta) \cot (\beta+\emptyset)}
$$

Fig. 2. McKyes Soil cutting model.

\section{3-Sigma Methodology for calculating the digging force with uncertainty}

When the digging process, there are three factors of uncertainty: changeability of techniques digging, the variability of the soil properties and the inaccuracy of the soil-tool interaction model. The techniques digging can be described by the rake angle $\alpha$ and the digging depth $\mathrm{d}$. Thus, the loads acting on the elements of the working equipment of the excavator will be determined only when the properties of the soil are uncertain at the greatest digging depth and the rake angle.

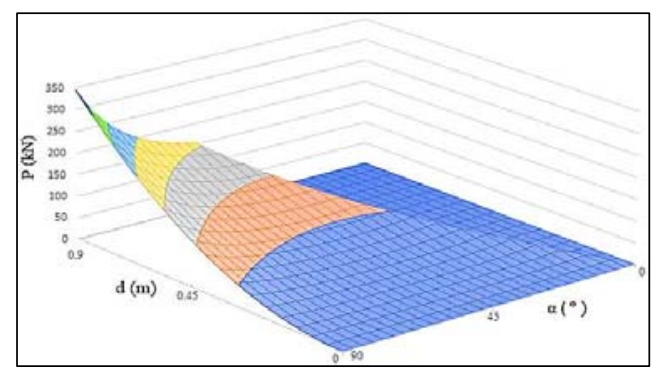

Fig. 3. Change of digging force depending on the digging depth and digging angle.

The calculation of all values of the digging force acting on the bucket by the Monte Carlo method is the process of solving the problems of optimizing the elements of the excavator working equipment at intervals of undetermined soil parameters. Table (1) shows the lower and upper limits of uncertain parameters of soil properties. These values were taken depending on the type of soil in Syria.

Table 1. Uncertain soil parameters and them lower/upper limits [20]

\begin{tabular}{|c|c|c|c|}
\hline Parameter & Symbol & min & max \\
\hline soil unit weight $\left[\mathrm{kN} / \mathrm{m}^{3}\right]$ & $\gamma$ & 15.7 & 19.13 \\
\hline Soil cohesion $[\mathrm{kPa}]$ & $\mathrm{c}$ & 16 & 24 \\
\hline Soil adhesion[kPa] & $\mathrm{ca}$ & 3 & 13 \\
\hline Soil internal friction angle [degree] & $\varnothing$ & 25 & 35 \\
\hline Soil-bucket friction angle [degree] & $\delta$ & 13 & 23 \\
\hline Digging depth[m] & $\mathrm{d}$ & - & 0.9 \\
\hline Digging angle [degree] & $\alpha$ & - & 90 \\
\hline
\end{tabular}


values of force obtained by the Monte Carlo method are global maximum values and are very low probability to occur. Using the (3 Sigma) method shown in Figure (4), it can be seen that the acceptance of the greatest value of the force with the probability of belonging to the interval $[-\infty, \mu+3 \sigma]$, the element design will be designed with a safety probability of $99.87 \%$ [21]. The arithmetic mean $(\mu)$ and standard deviation $(\sigma)$ of the digging force are calculated based on the Monte Carlo simulation results, $\mu=138000$, $\sigma=47500$, Therefore, the force will be applied when the optimization: $\mathrm{P}=\mu+3 \sigma=280$ $[\mathrm{kN}] \in[-\infty, \mu+3 \sigma]$.

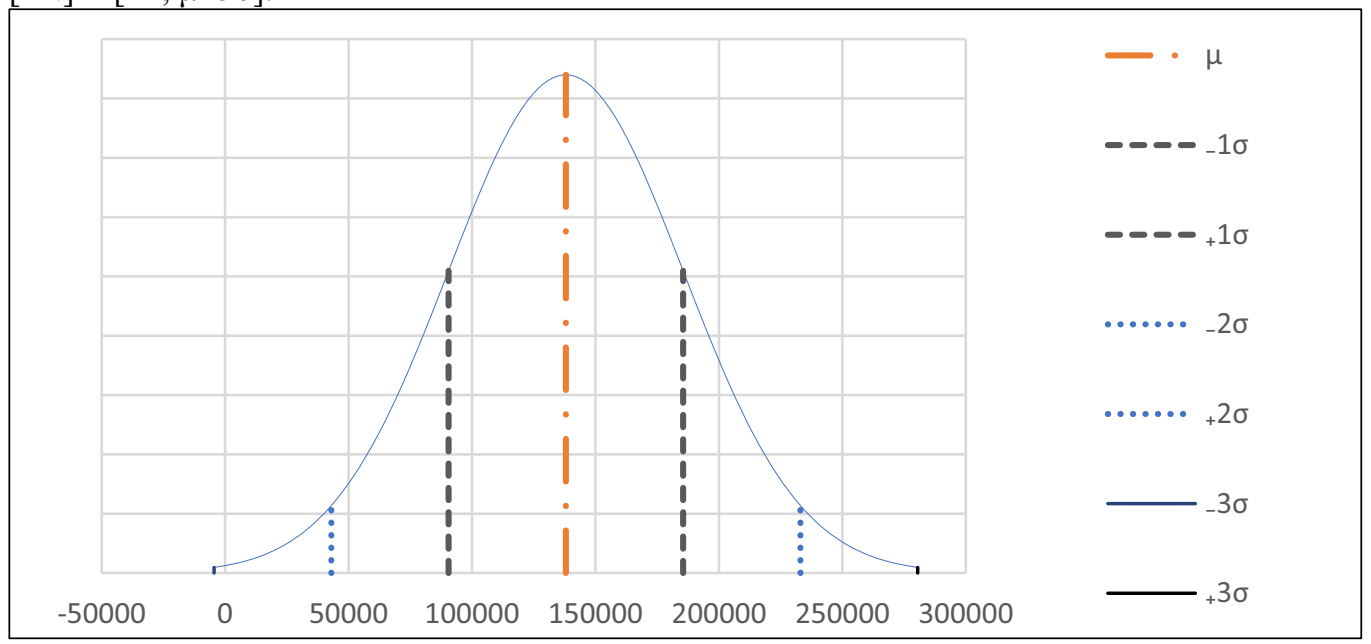

Fig. 4. Normal distribution of values of digging force

\section{Static analysis of stick of excavator VOLVO EC460}

The magnitude and direction of the digging forces acting on the bucket teeth usually change in the actual digging process. After calculating the magnitude of digging force, its direction is determined by the dynamic model of the working equipment, taking into account the limit conditions of the hydraulic system and limit conditions of tipping and slipping of the excavator [22]. The forces acting on each element are then calculated by static equilibrium analysis using the equations:

$$
m_{i} g_{i}+\sum F_{j}^{i}=0 ; \quad r_{g i} \times m_{i} g_{i}+\sum r_{j}^{i} \times F_{j}^{i}+M_{r}=0, \quad i=2,3,4
$$

A model of the stick of a VOLVO EC460 excavator is created in SolidWorks with real dimensions [23] for analyzing the stress-strain of the stick. The material of the stick st 52-3 was chosen [24]. Mechanical properties are shown in the table. 2.

Table 2. Mechanical properties of (ST 52-3) according to DIN 17100

\begin{tabular}{|c|c|c|}
\hline Property & value & unit \\
\hline Density & 7900 & $\mathrm{Kg} / \mathrm{m}^{3}$ \\
\hline Young's modulus & 210000 & $\mathrm{MPa}$ \\
\hline Poisson's ratio & 0.3 & -- \\
\hline Tensile strength & 700 & $\mathrm{MPa}$ \\
\hline Yield strength & 450 & $\mathrm{MPa}$ \\
\hline
\end{tabular}


The finite element analysis of the stick model carried out under the action of the forces calculated in each joint. The results of the analysis are shown in Figure 5.

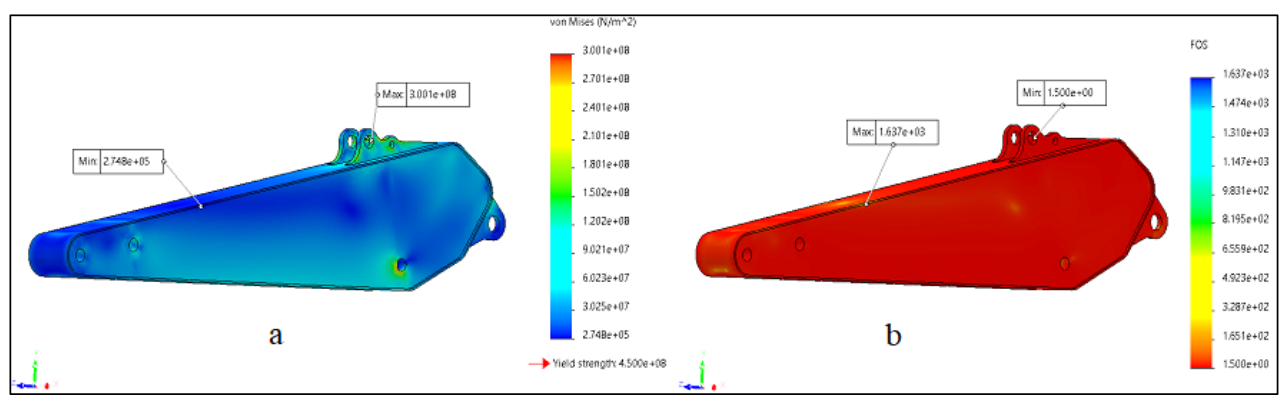

Fig. 5. Distribution of stress (a) and factor of safety (b) of the stick structure.

Can be seen that the stresses are concentrated in the hinge points connecting the stick and hydraulic cylinder of bucket, and in the lugs connecting the stick and hydraulic cylinder of stick. The stresses in the plates of the structure of stick are very low. The maximum stress of $300[\mathrm{MPa}]$ in the lugs connecting the stick and the hydraulic cylinder of bucket, which will reduce the safety margin of the structure $\{\mathrm{S}=1.5<[\mathrm{S}]=2\}$. Thus, it is necessary to optimize the stick structure.

\section{Optimization design of an excavator stick}

Structural optimization is the aim of finding your best possible design parameters which also satisfy the design requirements. It can reduce the maximum stresses in the crosssections of the structure, thereby increasing the safety margin of the structure under the same loading conditions.

Thicknesses of stick plates are chosen as design variables, as shown in Figure 6. Thicknesses of plate and lug are considered separate variables as they are individually manufactured and assembled by welding. Bounds of the design variables for the stick structure shown in table 3. Optimization problem is formulated as follows:

$$
\begin{gathered}
\min \sigma+m_{p} \\
\text { constraints: } \quad t_{\min }<t_{i}<t_{\max }, \quad i=1, \ldots, 9 \\
S \geq 2
\end{gathered}
$$

where, $\boldsymbol{\sigma}$ : maximum stress; $\boldsymbol{m}_{\boldsymbol{p}}$ : mass of stick; $\boldsymbol{t}_{\boldsymbol{i}}$ : thickness of plate $i ; \boldsymbol{S}$ : factor of safety.

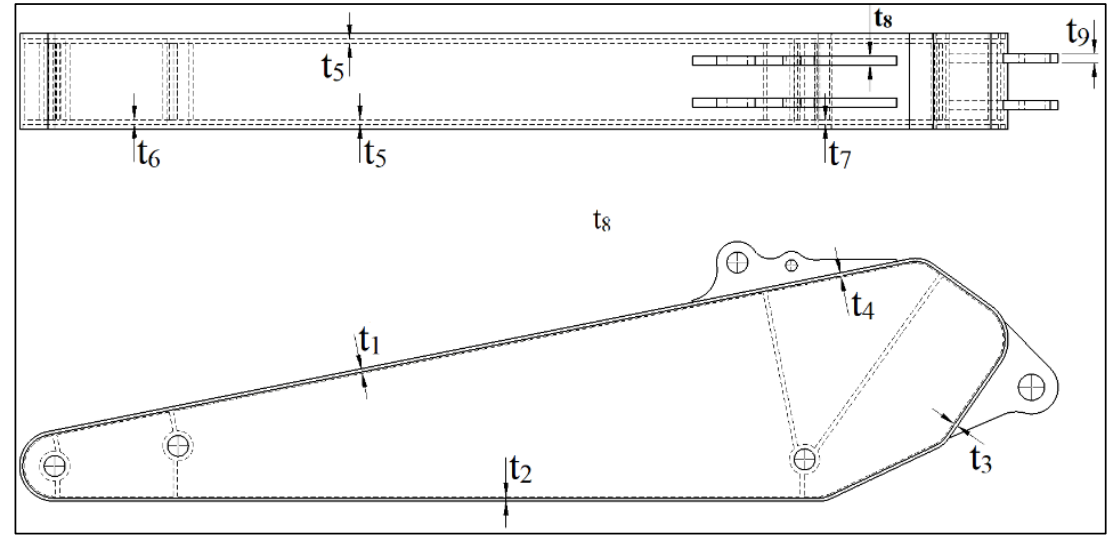

Fig. 6. Schematic diagram of the stick structure and design variables. 
Table 3. The bounds of design variables for the stick structure

\begin{tabular}{|c|c|c|c|c|c|c|c|c|c|}
\hline $\mathrm{t}_{\mathrm{i}}$ & $\mathrm{t}_{1}$ & $\mathrm{t}_{2}$ & $\mathrm{t}_{3}$ & $\mathrm{t}_{4}$ & $\mathrm{t}_{5}$ & $\mathrm{t}_{6}$ & $\mathrm{t}_{7}$ & $\mathrm{t}_{8}$ & $\mathrm{t}_{9}$ \\
\hline Min & 8 & 8 & 8 & 8 & 8 & 15 & 15 & 25 & 30 \\
\hline Max & 20 & 25 & 25 & 23 & 22 & 35 & 35 & 45 & 50 \\
\hline
\end{tabular}

\section{Optimization results}

The gradient method was chosen for optimization. This method calculates an approximate gradient to change the design variables to move more directly towards the optimum.

Table 4 show the comparisons between the initial and optimal design variables (thicknesses of plate) of the stick structure. The results of the finite element analysis of the optimal stick are shown in Figure 7. It shows that the handle is safe after optimization and the factor of safety $S_{\min }=2$, and the stress distribution is better.

Table 4. Initial and optimal values of design variables for the stick structure

\begin{tabular}{|c|c|c|c|c|c|c|c|c|c|}
\hline $\begin{array}{c}\text { design } \\
\text { variable }\end{array}$ & $\mathrm{t}_{1}$ & $\mathrm{t}_{2}$ & $\mathrm{t}_{3}$ & $\mathrm{t}_{4}$ & $\mathrm{t}_{5}$ & $\mathrm{t}_{6}$ & $\mathrm{t}_{7}$ & $\mathrm{t}_{8}$ & $\mathrm{t}_{9}$ \\
\hline $\begin{array}{c}\text { initial value } \\
{[\mathrm{mm}]}\end{array}$ & 15 & 18 & 18 & 15 & 15 & 21 & 21 & 30 & 40 \\
\hline $\begin{array}{c}\text { Optimal } \\
\text { value }\end{array}$ & 14 & 22 & 15 & 16 & 13 & 18 & 17 & 34 & 45 \\
\hline $\begin{array}{c}\text { Increment } \\
{[\%]}\end{array}$ & -6.67 & 22.22 & -16.67 & 6.67 & -13.3 & -14.3 & -19 & 13.3 & 12.5 \\
\hline
\end{tabular}

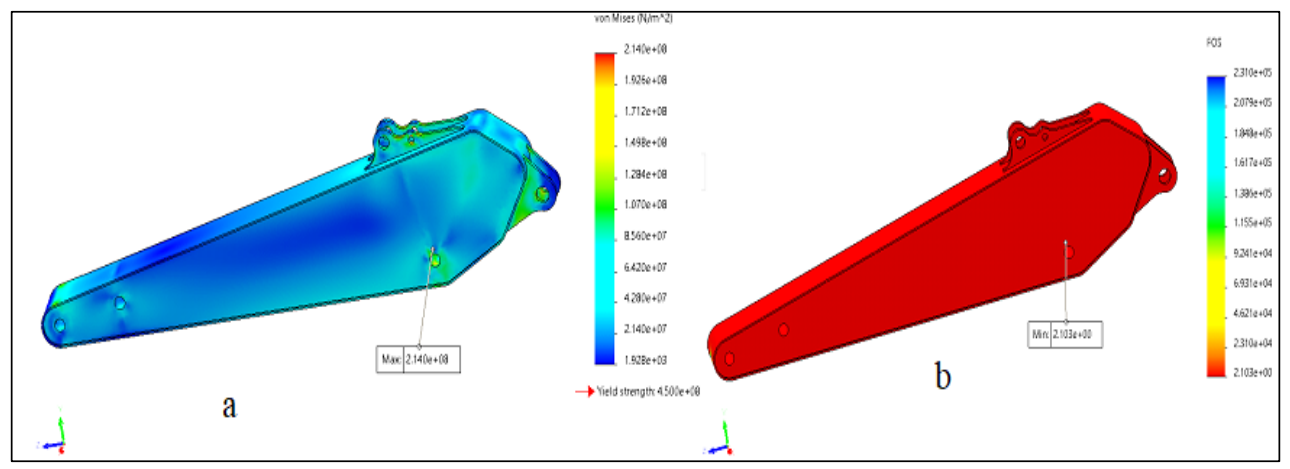

Fig. 7. Distribution of stress (a) and factor of safety (b) of the optimal model of the stick structure.

\section{Conclusions:}

The Monte Carlo method allows to determine the loads design on the working equipment of the excavator regardless of the operating mode of the excavator (do not need to know which hydraulic cylinder is active) in order to design or optimize elements with $99.87 \%$ confidence.

The results show that the weight of the optimal stick of excavator VOLVO EC460 was reduced with $2014.27 \mathrm{~kg}$ to $2365 \mathrm{~kg}$, i.e., it was reduced by $14.83 \%$, and the maximum stress is 214 [MPa] i.e., it was reduced by $28.67 \%$, and the minimum factor of safety $\mathrm{S}=$ 2.1. Thus, from the results of the analysis, using this optimization method the structure of an element can be obtained element with good durability and light weight. 


\section{References}

1. P.M. Babu, K. Sreenivas, Fatigue analysis and design optimization of a digger arm, IJMERR, v. 3(4), pp. 527-532 (2014).

2. A.M. Babu, Static force analysis of mini hydraulic backhoe excavator and evaluation of bucket capacity, digging force calculations, IJERA, v. 9, pp. 25-32 (2015).

3. A.S. Lomate, S. Biradar, K.K. Dhumal, A. Waychal, Design and Shape Optimization of Excavator Bucket, IRJET, v. 3(8), pp. 1423-1429 (2016)

4. P. Padman, S. Battuwar, K. Kini, A. Kulkarni, Optimization of the Boom of an Excavator, IJIRSET, v. 7(9), pp. 9662-9673 (2018).

5. R.B. Sarode, S.S. Sarawade, Structural Optimization of Excavator Bucket Link, IOSR, v. 3, pp. 10-16 (2016).

6. B.P. Patel, J.M. Prajapati, Evaluation of bucket capacity, digging force calculations and static force analysis of mini hydraulic backhoe excavator, machine design, 4(1), pp. 59-66 (2012).

7. S. Blouin, A. Hemami, M. Lipsett, Review of resistive force models for earthmoving processes, Journal of Aerospace Engineering, 14(3), pp. 102-111 (2001).

8. B. Park, Development of a virtual reality excavator simulator, (Virginia Tech, Blacksburg, 2002).

9. K. Awuah-Offei, S. Frimpong, Efficient cable shovel excavation in surface mines, Geotech Geol Eng, v. 29, pp. 19-26 (2011).

10. В. П. Павлов, Алгоритм расчета силь и энергоемкости резания грунта по траектории большой кривизны, Вестник Воронежского государственного технического университета, 7(1), (2011).

11. S. Singh, Learning to predict resistive forces during robotic excavation, IEEE, v. 2, pp. 2102-2107 (1995).

12. N. Bennett, A. Walawalkar, M. Heck, C. Schindler, Integration of digging forces in a multi-body-system model of an excavator, P I MECH ENG K-J MUL, v. 230(2) (2015).

13. I. Palomba, D. Richiedei, A. Trevisani, E. Sanjurjo, A. Luaces, J. Cuadrado, Estimation of the digging and payload forces in excavators by means of state observers, MSSP, v. 134, 106356 (2019).

14. Young Bum Kim, Junhyoung Ha, Hyuk Kang, Pan Young Kim, Jinsoo Park, F.C. Park, Dynamically optimal trajectories for earthmoving excavators, Automation in Construction, v. 35, pp. 568-578 (2013).

15. Tao Ni, H. Zhang, Changzhi Yu, Dingxuan Zhao, Songyue Liu, Design of highly realistic virtual environment for excavator simulator, Computers \& Electrical Engineering, v. 39(7), pp. 2112-2123 (2013).

16. Jin Chen, Xiaoping Pang, Xiaoping Pang, Digging performance characterization for hydraulic excavator considering uncertainty during digging operation. Proceedings of the Institution of Mechanical Engineers, SAGE, v. 232(5), pp. 857-871 (2017).

17. J.V. Perumpral, R.D. Grisso, C.S. Desai, A soil-tool model based on limit equilibrium analysis, ASABE, v. 26(4), pp. 991-995 (1983).

18. D.R.P. Hettiaratchi, B.D. Witney, A.R. Reece, The calculation of passive pressure in two-dimensional soil failure, Journal of Agricultural Engineering Research, v. 11(2), pp. 89-107 (1966).

19. E. McKyes, O.S. Ali, The cutting of soil by narrow blades, Journal of Terramechanics, v. 14(2), pp. 43-58 (1977).

20. Kuteni Jad Al Karim Hamad, Dissertation (RSL, Moscow, 2020). 
21. K. Shimoyama, A. Oyama, K. Fujii, Development of multi-objective six sigma approach for robust design optimization, JAIS, v. 5(8), pp. 1-27 (2008).

22. F. Flores, A. Kecskeméthy, A. Pöttker, Workspace analysis and maximal force calculation of a face-shovel excavator using kinematical transformers, $12^{\text {th }}$ IFToMM World Congress, Besancon, pp. 1-6 (2007).

23. Volvo Construction Equipment Group, Ref. No. 2124351621 English, global Printed in Korea 2000.09-1 KOR Volvo, Seou.

24. A. Erklig, E. Yeter, The Improvements of the Backhoe-Loader Arms, MNSMS, v. 03(04), pp. 142-148 (2013). 